\title{
Artigos
}

\section{Olhar discente e a formação em Odontologia: interseções possíveis com a Estratégia Saúde da Familia}

The perspective of students and dental education: possible intersections with the Family Health Strategy (abstract: p. 16)

Mirada discente y la formación en Odontología: intersecciones posibles con la Estrategia Salud de la Familia (resumen: p. 16)

Franklin Delano Soares Forte ${ }^{(a)}$

<franklin@ccs.ufpb.br>

Aída Albuquerque Pontes ${ }^{(b)}$

<aidapontesaida@gmail.com>

Hannah Gil de Farias Morais ${ }^{(\mathrm{c})}$

$<$ hannah_gil@hotmail.com>

Ailma de Souza Barbosa(d)

<ailmabarbosa@gmail.com>

Otacílio Batista de Sousa Nétto(e)

<otanetto2@gmail.com>

\author{
(a) Departamento de Clínica e Odontologia \\ Social, Centro de Ciências da Saúde \\ (CCS), Universidade Federal da Paraíba \\ (UFPB). Campus universitário I, Castelo \\ Branco. João Pessoa, PB, Brasil. \\ 58051-900. \\ (b) Cirurgiã-dentista. João Pessoa, PB, \\ Brasil. \\ (c) Cirurgiã-dentista. Patos, PB, Brasil. \\ (d) Cirurgiã-dentista. João Pessoa, PB, \\ Brasil. \\ (e) Departamento de Patologia e Clínica \\ Odontológica, CCS, Universidade \\ Federal do Piauí. Teresina, PI, Brasil.
}

Objetivou-se compreender a percepção dos estudantes de Odontologia de uma instituição pública brasileira sobre a inserção desses na concretude do Sistema Único de Saúde (SUS), em particular nos territórios da Estratégia Saúde da Família (ESF), e as possíveis contribuições desse processo nas suas formações acadêmicas. É um estudo de caso analítico, de abordagem qualitativa, realizado com discentes, mediante grupos focais com roteiros semiestruturados e associados à análise de portfólios produzidos por esses sujeitos pela análise de conteúdo. A partir do olhar do graduando, ora protagonista, ora coadjuvante, observaram-se elementos importantes na perspectiva do fortalecimento do SUS e simultaneamente da sua própria formação, no diapasão da integração ensino-serviçocomunidade. Os discentes percebem o território da ESF como vivo e potente cenário de aprendizado que aproxima o estudante dos serviços de saúde e seus usuários.

Palavras-chave: Sistema Único de Saúde. Atenção básica. Ensino em Odontologia. Aprendizagem. 


\section{Introdução}

Em um contexto de novas elaborações conceituais para formação superior em Saúde, a Organização Mundial de Saúde (OMS) ${ }^{1}$ sistematizou recomendações de novos delineamentos curriculares, articulando-os e aproximando-os intencionalmente das necessidades concretas das populações usuárias dos sistemas públicos de saúde o SUS, no caso brasileiro - buscando um diálogo intersetorial proativo entre atores responsáveis pelas políticas de saúde e educação. Essas propostas miram na imagemobjetivo factível de uma formação profissional com maior sentido de compromisso social, sem perda da qualidade tecnocientífica, em um processo epistêmico que aceita e imprime si mesmo como desafio e as palavras-chaves em curso: transformação, mudança e avaliação.

Nesse sentido, o conceito de "educação baseada na comunidade" tem sido proposto com foco em alguns pressupostos: promoção da saúde e a responsabilidade social na formação em saúde. Compreende-se educação baseada na comunidade como oportunidade de aprender com a e na comunidade e interpreta-se a responsabilidade social do aparelho formador como aquela que, entre outros aspectos, percebe a comunidade e seus usuários não como meros repositórios das boas intenções e ações acadêmicas, mas como parceiros efetivos e com voz ativa sobre questóes essenciais que dizem respeito a suas condiçôes de saúde, aos respectivos determinantes e, por conseguinte, as suas vidas².

Entre os principais desafios para a adequada formação em saúde está a articulação efetiva entre setores que gestam as instituiçôes da educação superior (IES) e o da saúde, tidos como diferentes mundos (ensino e trabalho) ${ }^{3}$. Articulação que dissipe a tradição consolidada de um diálogo pessoal-utilitarista de parte a parte, ou mesmo a ausência dele. Alguns estudos relatam experiências de formação em Odontologia com base na comunidade em diversas partes do mundo ${ }^{4-11}$, com o desenvolvimento de competências técnicas e também relacionais.

Experiências formativas com base na comunidade são materializadas a partir da inserção dos graduandos em estágios externos aos domínios clínicoterritoriais e administrativos das instituições de ensino. São vivências em geografias institucionalmente ligadas ao poder público, mediadas por convênios ou outras formas de cooperação. Essas experiências contribuem para desenvolvimento de competências desejáveis: comunicação, autoconfiança e habilidades clínicas, além de habilidades culturais $^{9-12}$.

Nesse sentido, fomenta-se a construção de diálogo em prol de objetivos comuns, dificilmente alcançados por um desses setores isoladamente, em uma relação na qual se revela e se enfrenta parte das fragilidades brasileiras na oferta de açóes e serviços de saúde e na distribuição geográfica dos profissionais de nível superior, tendo-se em mente a construção do SUS ${ }^{13}$. Nesse interim, devem ser consideradas questôes culturais e sociais presentes não só na elaboração das propostas pedagógicas, mas também as que atravessam a formação em Odontologia, no que se refere ao elenco dos cenários de aprendizagens ${ }^{12}$.

No Brasil, a formação em Odontologia esteve fundamentada consensualmente em currículos conservadores; tradicionais; repletos de ideias-dogmas; e marcados pela separação entre ciclos (básico e profissionalizante) impermeáveis e incomunicáveis entre si, pela hegemonia dos aspectos biológico e artesanal do fazer profissional, por uma 
ênfase valorativa nas especializações clínicas fundantes e pela história única do mercado privado como destino "natural” dos egressos. Os acúmulos da Reforma Sanitária, a criação e fortalecimento do SUS e resultados do histórico modo de formação e atuação profissional, refletidos na saúde bucal da população, são efetivamente as condições de possibilidade existentes para transformar, inovar ou (re)inventar essa formação ${ }^{13}$.

Com advento da Lei de Diretrizes e Bases da Educação, em 1996, e a proposição das Diretrizes Curriculares Nacionais (DCN) para cursos de Odontologia, contemplou-se uma carta de intençốes, um perfil esperado do egresso, competências gerais e específicas a serem alcançadas e outras orientações na proposição dos projetos pedagógicos ${ }^{14} . \mathrm{Na}$ perspectiva da atenção primária orientada pela ESF, espera-se desenvolver habilidade e competências como capacidade para o trabalho em equipe; reconhecimento do aprender a aprender como fomento da educação permanente; compreensão de forma ampliada do processo saúde-doença e sofrimento humano; capacidade à avaliação, planejamento e desenvolvimento de intervençôes preventivas e reabilitadoras conforme nível de atenção no contexto do SUS, dentro de uma visão integral; e trabalho em equipe com valores éticos e culturais.

Nesse contexto, a ESF como delineamento organizacional para reorganizar a atenção primária, que surge em um contexto de políticas sanitárias nacionais (da atenção básica e de promoção de saúde), reorienta o trabalho na perspectiva da produção de cuidado, ancorado, entre outros, na multiprofissionalidade e intersetorialidade ${ }^{15-19}$. Em 2004, a Política Nacional de Saúde Bucal buscou resgatar a importância da saúde bucal no contexto da saúde e equacionar uma dívida histórica de desassistência e invisibilidade das condições de saúde bucal da população enquanto ação pública do Estado brasileiro. A inserção da equipe de saúde bucal (EqSB) na Atenção Primária à Saúde (APS), compondo a equipe multiprofissional da ESF, deu um impulso à Odontologia no setor público, no qual sempre teve um papel marginal e secundário ${ }^{20}$.

A ESF se organiza com base territorial, consentaneamente geográfica, burocrática, demográfica, humana, social e cultural, sendo infiltrada por muitos tensionamentos ${ }^{21}$. Nessa polifonia, o cuidado em saúde materializa-se na gestão intercambiável de ações de promoção, prevenção e atenção à saúde, considerando a realidade da vida ${ }^{22}$, os agires leigos nos seus próprios itinerários de cuidado, e reconhecimento de uma sabedoria popular que em diversas ocasiôes assume que "a fortaleza dos mais vulneráveis é o seu tempo lento" 21 .

Estudos revelaram que a inserção de estudantes em territórios reais de aprendizagem foi significativa para formação no que diz respeito ao amadurecimento pessoal e à possibilidade de qualificar diversas dimensóes do perfil profissional ${ }^{22}$ pelas oportunidades de aplicação de conhecimentos e habilidades aprendidos na universidade ${ }^{23-27}$; e pelo contato com sujeitos, famílias, comunidade e território em seu próprio contexto e com a realidade do mundo do trabalho e da vida, o que expressa a valorização da experiência extramuros, em especial nos serviços do $\mathrm{SUS}^{28}$.

A polissemia da inserção do estudante no território da ESF, por meio de estágios supervisionados, e a contribuição destes para o processo de formação merece ser debatida e analisada em relação à inovação no desenho formativo e às repercussões na 
produção do cuidado sobre múltiplos pontos de vista (o técnico, ainda hegemônico, e o social, que progressivamente se insere neste campo).

\section{Métodos}

O estudo teve abordagem qualitativa e buscou explorar os sentidos atribuídos pelos estudantes sobre os estágios supervisionados que acontecem na ESF. A opção por uma pesquisa ancorada em informaçóes qualitativas privilegiou as visóes, as percepções e as impressões de estudantes sobre a integração ensino-serviçocomunidade $^{29}$ e, a partir destas, buscaram-se interpretações plurais.

Para exploração do campo, realizou-se um estudo de caso ${ }^{30}$ não unívoco, mas intencionalmente inseminado pelo atributo da imaginação sociológica ${ }^{31}$, com objetivo expresso de não apenas apresentá-lo descritivamente, mas também analisar aspectos dos fenômenos sociais envolvidos, desvelando-os em camadas de compreensão e interpretação ${ }^{32}$. Como os estágios supervisionados acontecem no cotidiano do SUS, o método estudo de caso "modificado" contribui para explicar relaçôes causais, intencionais ou não, em "intervenções da vida real”, tendo como pressuposto a integração ensino/serviço/comunidade.

\section{Cenário da pesquisa}

A Unidade de Saúde da Família (USF), cenário do estudo, pertence a um município do Nordeste do Brasil com 791.438 habitantes, cobertura de 86,89\% de ESF, $100 \%$ de cobertura de agentes comunitários de saúde (ACS) e cobertura de 78\% da EqSB. Selecionou-se a USF com uma ESF com 10 ACS, cenário de aprendizagem dos cursos de Odontologia, Enfermagem, Fonoaudiologia, Nutrição e Medicina há mais de dez anos e participação da equipe em todos os programas de reorientação da formação (PRO-Saúde I, PET-Saúde, PET-GraduaSUS).

O currículo do curso de Odontologia da IES foi implantado em 2002 procurando articular a formação para o SUS com estágios supervisionados desde o primeiro ano. A perspectiva é a do desenvolvimento da integralidade do cuidado e de açôes intersetoriais, constitutivas da saúde coletiva brasileira (em seus saberes epidemiológicos; políticos; de planejamento e gestão de serviços; e aportes das ciências sociais e humanas, que abrem o horizonte para uma perspectiva interpretativa, na qual caibam cultura, linguagem, símbolos e representações identitárias de uma população em seu território e seus significados).

Para alcançar os objetivos de aprendizagem dos estágios, são utilizadas preponderantemente metodologias ativas ${ }^{33}$, com aprendizado centrado no estudante e nas demandas vindas da equipe de saúde da família (EqSF). A prática pedagógica está ancorada no conceito de metodologias ativas discutido por Mitre et al. ${ }^{34} \mathrm{e}$ referencial teórico da pedagogia da autonomia de Freire ${ }^{35}$.

O planejamento das atividades é descentralizado e com participação coletiva e comunitária de representantes dos equipamentos sociais adscritos à USF, propiciando a compatibilização das agendas, em uma lógica que mira a responsabilidade social e a 
valorização da USF como cenário efetivo de aprendizagem e de produção simbólica e concreta do cuidado em saúde.

Nesse processo de amadurecimento e fortalecimento da relação interinstitucional, o curso propôs uma nova matriz pedagógica, pari passu, a Secretaria Municipal de Saúde tem organizado, desde 2005, a construção e remodelação permanente do Sistema Saúde/Escola.

Os estudantes são convidados e estimulados a assumir o protagonismo de sua formação e a enfrentarem um considerável e permanente desafio: construir autonomia nas palavras e, sobretudo, nas ações. A inserção nos serviços acontece em progressiva complexidade, buscando não considerar esses dispositivos apenas do ponto de vista meramente funcionalista ${ }^{36}$. As atividades problematizam a materialidade histórica da presença de um serviço de saúde de natureza pública, como esforço de consolidação do SUS em seus princípios doutrinários e organizativos e como campo de interesses e disputas de poder, tanto visíveis quanto ocultas, bem como luta por constituir-se como parte de um processo civilizatório ${ }^{37,38}$.

Os cotidianos vivos dos serviços de saúde e dos equipamentos sociais do entorno são refletidos na perspectiva da ação-reflexão-ação, buscando um aprendizado individual e coletivo. $O$ processo de trabalho na EqSF é orientado não exclusivamente pela perspectiva do previamente planejado, mas com flexibilidade e abertura ao inesperado. Há um cuidado reiterado quando alunos e professores estão no interior dos territórios em respeitar e não julgar/condenar o que está ali colocado e muitas vezes é resistente e reticente às nossas tentativas de aproximação/intervenção.

Empoderar-se aqui significa reconhecer e assumir o muito que não sabemos, que nossos saberes são apenas parte do caminho e que uma outra parte está por se conhecer ora no chão empoeirado, calçado com paralelepípedos ou asfalto-esburacados; ora nos ditos, interditos e não ditos dos territórios simbólicos e imateriais da vida e do cuidado. Procedimentos coletivos em saúde bucal procuram a diversificação dos métodos, cenários e público-alvo ${ }^{39}$. O processo de avaliação visa oportunizar a reflexão e crítica sobre o vivenciado. Para tanto, a opção foi pelos portfólios reflexivos.

\section{Sujeitos}

No ano letivo anterior à coleta de dados, matricularam-se 24 estudantes nos estágios supervisionados da Saúde Coletiva do segundo ano do curso, que foram convidados a participar dos grupos focais, dois em toda pesquisa, com seis a sete estudantes por grupo e duração média de quarenta minutos. Os estudantes deveriam estar regularmente matriculados e ter cursado os dois estágios supervisionados na mesma turma.

\section{Coleta de dados}

Utilizou-se, como técnica para coleta dos dados empíricos, o grupo focal (GF), definido como reunião para discussão organizada por um facilitador/pesquisador/ moderador para explorar um assunto específico. A discussão aconteceu a partir da interação entre os sujeitos, mediante questóes norteadoras ou disparadoras colocadas pelo facilitador ${ }^{40-42}$. 
O registro em áudio revelou que os dois grupos haviam respondido à questão da pesquisa e que a realização de novos grupos poderia apresentar redundância, uma vez identificado o alcance do platô de saturação para pesquisas qualitativas, que remete ao não surgimento de nenhuma ideia nova sobre o que está sendo estudado, tornando desnecessária a realização de novos grupos focais ${ }^{43,44}$.

Simultaneamente aos grupos focais, foi realizada a etapa de análise dos 24 portfólios de estudantes, no período de outubro de 2015 a maio de 2016, utilizando os mesmos critérios de exclusão e inclusão do grupo focal.

\section{Análise dos dados}

A transcrição dos registros dos grupos focais, bem como os portfólios, foram considerados pela análise de conteúdo ${ }^{45}$. Essa etapa consistiu em três polos cronológicos: pré-análise, exploração do material e tratamento dos resultados. A préanálise foi a fase de organização do material coletado, com o objetivo de identificar e sistematizar ideias iniciais. Em seguida, realizou-se leitura flutuante das falas do GF e dos portfólios. Essa fase estabeleceu um maior contato com os registros coletados para conhecê-los e analisá-los com maior profundidade. Em seguida, procedeuse à exploração dos registros e, por fim, ao tratamento dos resultados obtidos e interpretados. Na codificação, os dados foram transformados sistematicamente e agregados em unidades, que permitiram uma descrição das características pertinentes do conteúdo.

Por questóes éticas, as falas transcritas foram descaracterizadas, evitando possíveis elementos de identificação dos voluntários. Para apresentação dos dados, os discursos foram codificados com letras e numerados aleatoriamente, como GF 1 e 2; e Portfólio de 1 a 24 .

\section{Aspectos éticos}

O estudo obedeceu aos preceitos éticos da pesquisa envolvendo seres humanos, estabelecidos pela resolução no 466/2012, e aprovado pelo Comitê de Ética em Pesquisas com Seres Humanos, da instituição onde a pesquisa foi realizada (CAAE 42363315.9.0000.5188). Todos os participantes assinaram o Termo de Consentimento Livre e Esclarecido.

\section{Resultados e discussão}

A partir da análise das transcriçôes dos grupos focais, foram identificados os seguintes núcleos temáticos: Estágios Supervisionados em Saúde Coletiva: por uma Semântica Ampliada; Estratégia Saúde da Família: Território de Aprendizagem Recíproca; e Avaliação do Processo Ensino-Aprendizagem, que serão apresentados e discutidos em seguida. 
Um dos grandes desafios enfrentados pelo os que lidam com a materialização da integração ensino-serviço-comunidade é a viabilização sem intermitência dos estágios do ponto de vista jurídico-institucional. No caso em análise, há uma partilha histórica de legislaçôes sob forma de termos de cooperação/convênio celebrados entre as instituiçóes envolvidas. Esses documentos, construídos no exercício dialógico de interesses e responsabilidades, conciliam missões e agendas da IES-SMS em um movimento sinérgico e convergente entre diferentes poderes, saberes e atores. Essa parceria tem resistido ou sobrevivido às alternâncias democráticas nas gestóes municipal e universitária.

Garantir a inserção dos estudantes de forma gradativa no SUS é um compromisso assumido no projeto pedagógico, que envolve o desafio de transitar no espaço não acadêmico strictu sensu do SUS. O movimento acontece sempre na direção de uma experiência concreta e seus plurais significados. Assim, assume-se uma proposta pedagógica de formação com vínculo ao SUS e aos seus cenários de atenção à saúde ${ }^{46}$.

Alguns aspectos desse fluxo foram reconhecidos pelos próprios estudantes no grupo focal.

[...] a parte básica do curso de Odontologia, no início, é muito teórica, e o único contato que a gente tem é nos estágios. Eles são uma porta de entrada pra gente, onde podemos ter uma noção de como funciona o SUS. (GF 2)

[...] quando você problematiza, você associa a prática com a teoria. É muito mais que uma transmissão de conhecimentos só em sala de aula [...]. Nos estágios, a gente vê de perto como aquilo funcionava, que é realmente um serviço onde as coisas acontecem. (GF 1)

Assim, a busca pelas aprendizagens significativas ${ }^{47}$ é colocada em ato como premissa de uma formação contextualizada com a organicidade da realidade, sanitária e social. $\mathrm{O}$ estágio supervisionado se configura como um elo entre a teoria e a prática, no qual se constrói a identidade profissional por ser um espaço rico de aprendizado ${ }^{46}$.

O encontro entre os construtos cognitivos, sociais e psíquicos dos estudantes e a ampla diversidade das experiências vividas no território oportunizam um processo educativo crítico-reflexivo, traduzido em novas elaboraçôes semânticas produzidas a partir do territorialmente construído. Aqui, destaca-se a importância de reconhecer, no território da ESF, as dinâmicas das interaçóes socioculturais, que atravessam a formação em saúde e a consequente produção do cuidado em saúde bucal ${ }^{48}$.

A formação que se desenlaça nos cenários de prática não elimina conflitos, mas rompe barreiras e fortalece a dialogicidade. Todos em alguma medida se transformam, não é algo simples nem absolutamente tranquilo, e este processo não significa aprovação tácita e consensual das experiências integradoras.

[...] todo contexto do sistema da saúde é complexo, quando você entra na universidade você entende, e quando você traz aquilo pra prática, muda tudo, parece que acende uma luz e ainda mais quando você associa prática com a teoria, é muito mais do que uma transmissão de conhecimentos só em sala de aula. (GF 1) 
Nesse sentido, destacam-se alguns aspectos importantes para aprendizagem significativa ${ }^{47}$ : o protagonismo do estudante no processo ensino-aprendizagem, o acúmulo de experiências e conhecimentos e o respaldo teórico-conceitual apropriado.

$\mathrm{Na}$ perspectiva freireana, a aprendizagem assume uma rubrica crítico-política e, ao mesmo tempo, compartilhada, emancipatória e produtora de autonomia dos sujeitos ${ }^{35}$. A problematização como estratégia possibilita ao estudante imersão no contexto explorado além da superfície, em um mergulho de águas profundas, oportuno não apenas para sua formação acadêmica, mas para seu futuro ingresso na profissionalização ${ }^{49}$. Neste horizonte, o SUS está presente não como utopia remota, principialista na teoria e sempre trágica no aparato comunicativo da grande mídia, mas como processo civilizatório em seguimento, política pública brasileira redutora de desigualdades e direito de cidadania, mais bem que malsucedida, ainda que longe de estar e ser o que gostaríamos.

Os estágios oportunizam a aproximação da formação do trabalho dos preceptores e de outros trabalhadores sanitários e minimizam a chance do olhar acadêmico enviesado, lançado sobre usuários que frequentam estes serviços. Dessa forma, contribuem com a consolidação e fortalecimento do SUS na APS orientada pela ESF $^{50-52}$, com convite para a prática colaborativa e trabalho em equipe, na medida em que os atores compartilham, em tese, compromissos com a comunidade, mediando o estabelecimento de escutas ${ }^{53}$.

[...] as pessoas têm uma visão da Odonto que faz procedimentos, e é tanto que a gente ia e as pessoas não entendiam e diziam "Ah, então, vocês são de Odonto e estão aqui fazendo o que com o ACS?” (GF 1)

[...] nos primeiros estágios, a gente pode pelo menos entender um pouco de como funciona aquilo, porque é totalmente diferente a vivência que eu tinha... (GF 1)

Para isso, os cursos de Odontologia precisam mais do que simplesmente reformular suas propostas pedagógicas, sobretudo currículos pensados e elaborados para oportunizar uma formação potente. É preciso ir além dos dispositivos conservadores e tradicionais do biopoder e suas intençôes-restriçôes de vigilância e clínica odontológica com subordinação dos corpos - com ou sem órgãos e bocas, e das bocas com ou sem dentes - e, assim, avançar em um movimento de aproximação e alianças entre os dois setores saúde e educação ${ }^{50,51}$, desdentarizando a Odontologia, humanizando-a.

$\mathrm{Na}$ narrativa foucaultiana sobre nascimento da clínica e dos micropoderes envolvidos, a estruturação secular da formação em saúde acontece e se perpetua a partir do olhar anátomo-clínico. Na perspectiva e no desejo de reorientação teórica, há um desafio e necessidade de deslizar esse olhar bio-odontológico para um olhar ampliado em mirada e cenários, que contemple sujeitos e o complexo processo humano de saúdedoença-cuidado ${ }^{39}$.

Assim, fomenta-se o desenvolvimento de competências, habilidades e atitudes, que nos primeiros estágios do curso visam à construção de um profissional promotor de 
saúde, compreensivo com sujeitos e suas interaçôes sociais e com um olhar para além das doenças bucais, no caminho uma abordagem pautada na integralidade ${ }^{14}$.

Acredito que um dos objetivos de todos esses estágios: conscientizar como trabalhar de forma humanizada, pensando nos pacientes de forma completa, planejar atividades de acordo com a realidade local, visando uma melhor qualidade de vida. (Portfólio 12)

\section{Estratégia Saúde da Família: Território de Aprendizagem Recíproca}

O movimento de integração dos setores educação, saúde e comunidade tem, entre outros desafios, o exercício da escuta, a formação de vínculos, o estabelecimento da empatia e a alteridade como princípios fundantes e entrelaçados entre interesses $\mathrm{da}$ formação em Odontologia e da atenção, considerando as demandas do território ${ }^{46,54,55}$.

Compreender a percepção dos estudantes envolvidos contribui para entender o papel da integração ensino-serviço-comunidade no modelo de atenção do município, bem como o impacto dessa experiência na formação em saúde ${ }^{12,23,46,51,52}$.

Ao concluir esse estágio, sinto-me capacitada a tomar atitudes que busquem promoção da saúde, educação em saúde, e saúde na comunidade. Compreendo a importância da atuação ampliada do CD (cirurgião-dentista) na ESF, visando à efetivação dos princípios e diretrizes preconizados pelo SUS. (Portfólio 24)

Pereira e Barcellos ${ }^{53}$ definem território em uma perspectiva integradora, como revelador de parte ou das dimensóes sociais (política, cultural e econômica), sendo fruto de uma relação complexa entre os processos sociais e o espaço geográfico, constituindo-se como depositório de atributos da população, lugar de responsabilidades e de atuaçôes compartilhadas, formando pessoas e construindo cidadania.

[...] é assim que descobrimos que intervir em saúde não requer um hospital, uma clínica ou grandes recursos. Requer apenas um olhar compreensivo e vontade de ajudar o outro. (Portfólio 24)

A visão crítica da gente melhorou muito, sobre o sistema mesmo, porque quando a gente entra, a gente entra não naquilo, mas o que falaram pra gente; entra com uma visão totalmente diferente. E quando você chega, que vê aquilo ali, que passa a estudar, você começa a ver que não é bem como falaram pra você... (GF 2)

Alguns estudos apontaram que os estágios proporcionam aos estudantes um amadurecimento na compreensão do SUS como espaço singular para desenvolvimento de práticas educativas e de promoção da saúde, que estimula a criatividade e inovação e, ao mesmo tempo, demanda propostas pedagógicas que mobilizam o saber a partir de um posicionamento ativo do estudante ${ }^{23-27}$. 
Educação em saúde que se aproxima da direção problematizadora ${ }^{49}$, menos no que diz respeito à clínica e mais como agentes promotores de saúde, que transformam o modo de edificar atenção à saúde. Esse aprendizado ocorre no desenrolar de atividades programadas, como visitas domiciliares, rodas de conversa na sala de espera e de estratégias de promoção de saúde (bucal), nos equipamentos adscritos à USF.

A visita domiciliar é uma forma eficaz de promover saúde em uma comunidade. Para isso, é necessária uma aproximação com os usuários, para que as necessidades de saúde dos mesmos sejam atendidas e suas expectativas, quanto ao cuidado, sejam satisfeitas. (Portfólio 24)

A sala de espera se mostrou um ambiente muito bom... propicia uma aproximação entre a comunidade e os serviços de saúde. Essas atividades também acolhem os usuários, melhoram a relação dos mesmos com os serviços, transformando um ambiente que era improdutivo num ambiente de promoção e prevenção da saúde... (Portfólio 23)

A educação em saúde assim compreendida é um processo dinâmico e, portanto, em construção $0^{35,49}$. O caminho da aprendizagem envolve saberes e práticas, não apenas sob uma perspectiva de linearidade normativa e unidirecional, "do doutor para o paciente'”, mas também envolvendo os sujeitos nas vivências, independentemente de seus papéis previamente assumidos ${ }^{23,54}$. Trata-se de uma pedagogia que se busca cúmplice e ao mesmo tempo "profana", que cativa e estimula a liberdade no exercício do ensinar e do aprender ${ }^{56}$.

\section{Avaliação do Processo Ensino-Aprendizagem}

O campo da avaliação do processo ensino-aprendizagem procura captar as aprendizagens que foram significativas. No caso dos estágios supervisionados da Saúde Coletiva, a avaliação foi pensada para oportunizar diferentes formas de manifestação e registro das experiências vividas, na perspectiva da avaliação formativa, tendo destaque os estudos de caso e os portfólios.

Os estudos de caso foram utilizados para avaliação, tendo em vista o nível esperado de conhecimento dos estudantes. Para a resposta dos casos-problema, textos em formato narrativo, descritivo ou dissertativo - e até crônicas - eram permitidos. Como matriz de resposta para o caso elaborado, era feita uma reflexão sobre os fatos apresentados, uma ponderação crítica sobre o vivenciado em ato e discutido na teoria.

Muito bom, os estudos de caso. Era bom porque você tinha que estudar a parte teórica, que tinham questóes que eram mais "fale os princípios que..." e a parte de você pensar como resolver o problema... (GF 2)

Os estudantes envolvidos aprendem e ensinam entre consensos e dissensos entre si e demais sujeitos nesse território, mediatizados pela diversidade humana, profissional ${ }^{35}$. Durante a vigência dos estágios, oportuniza-se um olhar mais atento sobre as estruturas sociais dispostas nas ruas, nas unidades de saúde, nos 
equipamentos sociais e casas visitadas. Nesse território urbano, estão expostos o curso das vidas, suas relações comunitárias, pobreza, exclusão, as desigualdades sociais produtoras de iniquidades em saúde, questóes ligadas a etnicidade e violências em suas diferentes manifestaçôes, mas também demonstrações de solidariedade e cumplicidade no enfrentamento de todas as dificuldades.

Além do estudo de casos-problema, o portfólio reflexivo foi utilizado como instrumento de acompanhamento e avaliação do estudante. O portfólio é um espaço de coleção de registros do aprendizado dessa trajetória, em um dado tempo, e surge como estratégia de avaliação e acompanhamento do estudante, na qual professor e estudante transformam suas formas de ver, pensar e agir, resultando em um real impacto na motivação, além de aprendizagem significativa ${ }^{57-59}$.

O que a gente tem de bom é a oportunidade de se expressar melhor no portfólio, porque a gente tem tempo para construir aquilo ali. Porque, às vezes, quando a gente discute em sala de aula, a gente discute de maneira sucinta. Mas, no portfólio, a gente tem um tempo maior para pensar, pra descrever, como também pra falar da percepção da gente sobre aquelas atividades realizadas... (GF 2)

Entretanto, na construção dos portfólios, os estudantes apontaram como fragilidade e desafio o pouco tempo para construir um material mais elaborado e mais reflexivo, limitando em tese a qualidade do resultado final.

E como ponto negativo do portfólio, assim, a gente começa fazendo bem direitinho, no começo do semestre. Só que, no final do semestre, a gente faz do jeito que dá, porque é final de semestre. Mas, isso é uma coisa que a gente enfrenta em toda disciplina: começa direitinho, mas, no final, vai atropelando, e a gente perde o fio da meada... (GF 1)

Outro aprendizado oportuno é constatar a ambiguidade da relação com o tempo, que é considerado vilão na execução do portfólio, na medida em que há um reconhecimento tácito que ele nunca será o ideal ou suficiente, dado que o calendário segue impessoalmente o seu próprio ciclo a despeito do nosso desejo e do compromisso estabelecido. Assim, é preciso encontrar tempo não só para mergulhar no círculo temporal da vida de um serviço de saúde, de um território em movimento, mas também para conciliá-lo com o tempo necessário às leituras, à reflexão e à escrita.

Talvez devesse haver maior articulação entre docentes e discentes, para assim definirem uma agenda compatível com os compromissos de outros componentes curriculares. Essa adaptação teria como objetivo evitar períodos de sobrecarga para o estudante, possibilitando uma aprendizagem menos sofrida, menos impessoal e uma entrega mais tranquila e favorável de trabalhos necessários.

Como este estudo foi baseado em fatos relatados pelos sujeitos, seria interessante que outras ferramentas de coleta de dados e outros tipos de estudo com base na observação participante, entrevistas e/ou com indicadores fossem realizados. $\mathrm{O}$ desejo finalístico é uma formação em Odontologia mais contextualizada, reflexiva e também humanizada, que observa, participa e analisa o mundo do trabalho lá fora, 
mas também se volta e se dobra sobre si mesma, não como estrutura enrijecida e enferrujada, mas como matéria viva, flexível; matéria-prima potente e contínua de formação de novas vidas entrelaçadas e integradas.

\section{Conclusão}

O território da ESF oportuniza experiências de ensino-aprendizagem extramuros, propiciando aos estudantes enxergar a APS como espaço para criação e invenção no desenvolvimento de práticas educativas de promoção da saúde e de uma clínica ampliada, que aproximam o serviço de saúde, a comunidade e a formação acadêmica. Os estudantes percebem os estudos de caso e portfólio como avaliação potente, embora reconheçam que o tempo e outras atividades do semestre fragilizam a produção de portfólio mais reflexivo e crítico. Os estágios supervisionados da Saúde Coletiva proporcionam a problematização e mobilizam o saber para um planejamento contextualizado, propiciando o desenvolvimento e aperfeiçoamento das competências e habilidades pessoais do estudante.

\section{Contribuições dos autores}

Franklin Delano Soares Forte, Aída Albuquerque Pontes, Hannah Gil de Farias Morais e Ailma de Souza Barbosa trabalharam na concepção do projeto de pesquisa, coleta, análise e discussão dos resultados do trabalho, revisão e aprovação da versão final do trabalho. Otacílio Batista de Sousa Nétto trabalhou na análise dos dados e participou ativamente da discussão dos resultados do trabalho, da revisão e da aprovação da versão final do trabalho.

\section{Agradecimento}

Ao Programa Institucional de Bolsas de Iniciação Científica (Pibic), do Conselho Nacional de Desenvolvimento Científico e Tecnológico (CNPq), pelo auxílio recebido.

\section{Direitos autorais}

Este artigo está licenciado sob a Licença Internacional Creative Commons 4.0, tipo BY (https://creativecommons.org/licenses/by/4.0/deed.pt_BR).

\section{Referências}

1. World Health Organization. Transforming and scaling up health professionals' education and training: WHO Education Guidelines 2013. Geneva: WHO; 2013.

2. Talaat W, Ladhani Z. Community Based education in health professions: global perspectives. Geneva: WHO; 2014.

3. Frenk J, Chen L, Bhutta ZA, Cohen J, Crisp N, Evans TE, et al. Health professionals for a new century: transforming education to strengthen health systems in an interdependent world. Lancet. 2010; 376(9756):1923-58. 
4. Hobson RS. A view of European challenges in dental education. Br Dent J. 2009; 206(2):65-6.

5. Hood JG. Service-learning in dental education: meeting needs and challenges. J Dent Educ. 2009; 73(4):454-63.

6. Piskorowski WA, Stefanac SJ, Fitzgerald M, Green TG, Krell RE. Influence of community-based dental education on dental students' preparation and intent to treat underserved populations. J Dent Educ. 2012; 76(4):534-9.

7. McQuistan MR, Mohamad A, Kuthy RA. Association between dentists' participation in charitable care and community-based dental education. J Dent Educ. 2014; 78(1):110-8.

8. Strauss RP, Stein MB, Edwards J, Nies KC. The impact of community-based dental education on students. J Dent Educ. 2010; 74(10):42-55.

9. Mashabi S, Mascarenhas AK. Impact of community externships on the clinical performance of senior dental students. J Dent Educ. 2011; 75(10):36-41.

10. Formicola AJ, Bailit HL. Community-based dental education: history, current status, and future. J Dent Educ. 2012; 76(1):98-106.

11. Coe JM, Best AM, Warren JJ, McQuistan MR, Kolker JL, Isringhausen KT. Servicelearning's impact on dental students' attitude toward community service. Eur J Dent Educ. 2015; 19(3):131-9.

12. Costa RAH. O que se ensina aos futuros cirurgiões-dentistas? Um estudo de caso etnográfico sobre currículo e práticas escolares em odontologia [tese]. Rio de Janeiro: Escola Nacional de Saúde Pública, Fundação Osvaldo Cruz; 2009.

13. Vendruscolo C, Padro ML, Kleba ME. Integração ensino-serviço no âmbito do programa nacional de reorientação da formação profissional em saúde. Cienc Saude Colet. 2016; 21(9):2949-60.

14. Ministério da Educação (BR). Resolução CNE/CES no 3, de 19 de Fevereiro de 2002. Diretrizes Curriculares Nacionais do Curso de Graduação em Odontologia. Diário Oficial União. 4 Mar 2002.

15. Paim J, Travassos C, Almeida C, Bahia L, Macinko J. Saúde no Brasil: o sistema de saúde brasileiro: história, avanços e desafios. Lancet. 2011; 377(9779):11-31.

16. Ministério da Saúde (BR). Portaria n ${ }^{\circ} 2.488$, de 21 de Outubro de 2011. Aprova a Política Nacional de Atenção Básica, estabelecendo a revisão de diretrizes e normas para a organização da Atenção Básica, para a Estratégia Saúde da Família e o Programa de Agentes Comunitários de Saúde. Diário Oficial da União. 22 Out 2011.

17. Junqueira LAP. Descentralização, intersetorialidade e rede como estratégias de gestão da cidade. Rev FEA/PUC-SP. 1999; 1:57-72.

18. Ministério da Saúde (BR). Secretaria de Vigilância em Saúde. Redefine a Política Nacional de Promoção da Saúde. Portaria no 2.446 MS/GM, de 11 de Novembro de 2014. Brasília (DF): Ministério da Saúde; 2014.

19. Fausto MCR, Giovanella L, Mendonça $\mathrm{MH}$, Seidl H, Gagno J. A posição da estratégia saúde da família na rede de atenção à saúde na perspectiva das equipes e usuários participantes do PMAQ-AB. Saude Debate. 2014; 38(esp):13-33.

20. Pucca GA Jr, Gabriel M, Araújo ME, Almeida FC. Ten years of national oral health policy in Brazil: innovation, boldness, and numerous challenges. J Dent Res. 2015; 94:1333-7.

21. Santos M. Território, globalização e fragmentação. São Paulo: Hucitec; 1994. 
22. Werneck MAF, Senna MIB, Drumond MM, Lucas SD. Nem tudo é estágio: contribuiçốes para o debate. Cienc Saude Colet. 2010; 15(1):221-31.

23. Souza Nétto OB, Moura MS, Lima MDM, Lages GP, Mendes RG, Moura LFAD. O pró-saúde no curso de odontologia na Universidade Federal do Piauí: relato de uma vivência de cinco anos. Cienc Cuid Saude. 2013; 12(2):391-7.

24. Alves LA, Freires IA, Braga CC, Castro RD. Experiência exitosa na atenção odontológica à comunidade. Rev Bras Cienc Saude. 2012; 16(2):235-8.

25. Albuquerque VS, Gomes AP, Rezende AHA, Sampaio MX, Dias OV, Lugarinho RM. A integração ensino-serviço no contexto dos processos de mudança na formação superior dos profissionais da Saúde. Rev Bras Educ Med. 2008; 32(3):356-62.

26. Morita MC, Kriger L, Carvalho ACP, Haddad AE. Implantação das diretrizes curriculares nacionais em odontologia. 2a ed. Maringá: Dental Press, Abeno, OPS, MS; 2013.

27. Almeida AB, Alves MS, Leite ICG. Reflexôes sobre os desafios da odontologia no Sistema Único de Saúde. Rev APS. 2010; 13(1):126-32.

28. Silveira JLGC, Garcia VL. Mudança curricular em odontologia: significados a partir dos sujeitos da aprendizagem. Interface (Botucatu) 2015; 19(52):145-58.

29. Minayo MCS. O desafio do conhecimento: pesquisa qualitativa em saúde. São Paulo: Hucitec; 2015.

30. Yin RK. Estudo de caso: planejamento e métodos. 5a ed. Porto Alegre: Bookman; 2015.

31. Mills CW. A imaginação sociológica. 6a ed. Rio de Janeiro: Zahar; 1982.

32. Giddens A. Sociologia. 6a ed. Porto Alegre: Penso; 2012.

33. Anastasiou LGC, Alves LP. Processos de ensinagem na universidade: pressupostos para as estratégias de trabalho em aula. 3a ed. Joinville: UNIVILLE; 2004.

34. Mitre SM, Siqueira-Batista R, Girardi-de-Mendonça JM, Morais-Pinto NMM, Brandão CA, Pinto-Porto C, et al. Metodologias ativas de ensino-aprendizagem na formação profissional em saúde: debates atuais. Cienc Saude Colet. 2008; 13 Supl 2:2133-44.

35. Freire P. Pedagogia da autonomia: saberes necessários à prática educativa. 43a ed. São Paulo: Paz e Terra; 2011.

36. García JC. Medicina y sociedad. Las corrientes de pensamiento en el campo de la salud. Educ Med Salud. 1983; 17(4):363-97.

37. Góes FT, Machado LRS. Políticas educativas, intersetorialidade e desenvolvimento local. Educ Realidade. 2013; 38(2):627-48.

38. Elias N. O processo civilizador: uma história dos costumes. Rio de Janeiro: Jorge Zahar; 1994.

39. Nogueira MI, Guedes CR. Da graduação biomédica à medicina de família: aprendendo a se tornar um "médico da pessoa". Physis. 2013; 23(2):439-60.

40. Stalmeijer RE, McNaughton N, Van Mook WN. Using focus groups in medical education research: AMEE Guide no 91. Med Teach. 2014; 36(11):923-39.

41. Kitzinger J. The methodology of focus groups: the importance of interaction between research participants. Sociol Health Illn. 1994; 16(1):103-12.

42. Barbour RS. Making sense of focus groups. Med Educ. 2005; 39(7):742-50. 
43. Lincoln YS, Guba EG. Naturalistic inquiry. Beverly Hills: Sage; 1985.

44. Strauss A, Corbin J. Basics of qualitative research grounded theory procedures and technique. London: Sage publications; 1998.

45. Bardin B. Análise de conteúdo. São Paulo: Edições 70; 2011.

46. Bulgarelli AF, Souza KR, Baumgarten A, Souza JM, Rosing CK, Toassi RFC. Formação em saúde com vivência no Sistema Único de Saúde (SUS): percepções de estudantes do curso de odontologia da Universidade Federal do Rio Grande do Sul (UFRGS), Brasil. Interface (Botucatu). 2014; 18(49):351-62.

47. Ausubel D. Aquisição e retenção de conhecimentos: uma perspectiva cognitiva. Lisboa: Plátano Editora; 2000.

48. Arouca $\mathrm{R}$, Rego STA, Machado M. Das políticas de formação às salas de aula: reflexões sobre a questão curricular em odontologia. Rev Bras Odontol. 2007; 64(3-4):274-8.

49. Cyrino EG, Toralles-Pereira ML. Trabalhando com estratégias de ensino-aprendizado por descoberta na área da saúde: a problematização e a aprendizagem baseada em problemas. Cad Saude Publica. 2004; 20(3):780-8.

50. Toassi RFC, Davoglio RS, Lemos VMA. Integração ensino-serviço-comunidade: o estágio na atenção básica da graduação em odontologia. Educ Rev. 2012; 28(4):223-42.

51. Finkler M, Caetano JC, Ramos RFS. Integração "ensino-serviço" no processo de mudança na formação profissional em odontologia. Interface (Botucatu). 2011; 15(39):1053-70.

52. Warmiling CM, Rossoni E, Hugo FN, Toassi RFC, Lemos VA, Slavutzki SMB, et al. Estágios curriculares no SUS: experiências da faculdade de odontologia da UFRGS. Rev ABENO. 2011; 11(2):63-70.

53. Pereira MPB, Barcellos C. O território no programa de saúde da família. Hygeia 2006; 2(2):47-55.

54. Neta Aguiar A, Alves MSCF. A comunidade como local de protagonismo na integração ensino-serviço e atuação multiprofissional. Trab Educ Saude. 2016; $14(1): 221-35$.

55. Noro LRA, Torquato SM. Percepção sobre o aprendizado de saúde coletiva e o SUS entre alunos concludentes de curso de odontologia. Trab Educ Saude. 2010; 8(3):43947.

56. Larrosa J. Pedagogia profana: danças, piruetas e máscaras. 5a ed. Belo Horizonte: Autentica; 2013.

57. Rossato R. Século XXI saberes em construção. 2a ed. Passo Fundo: UPF; 2006.

58. Buckley S, Coleman J, Davison I, Khan KS, Zamora K, Malick S, et al. The educational effects of portfolios on undergraduate student learning: a best evidence medical education (BEME) systematic review. Med Teach. 2009; 31(4):282-98.

59. Cotta RMM, Costa GD. Instrumento de avaliação e autoavaliação do portfólio reflexivo: uma construção teórico-conceitual. Interface (Botucatu). 2016; 20(56):17183. 
The aim of this study was to understand the perception of dental school students at a public Brazilian institution about their practical insertion in the Brazilian National Health System (SUS), especially within the strategies of the Family Health System (FHS). Furthermore, the study gathered their impressions on how this experience contributed to their academic education. This was an analytical qualitative study conducted with focus groups of dental school students, using semi-structured scripts. Furthermore, the portfolios produced by the participants were submitted to content analysis. Based on the perspective of the graduating students, who sometimes took on leading roles and at others supporting roles, important elements were presented to strengthen SUS and simultaneously their own education, within the standard of integrating teaching/service/ community. The students perceived the FHS territory as a living and powerful context for learning that brought them closer to health services and their users.

Keywords: Brazilian National Health System. Primary health care. Dental education. Learning.

El objetivo fue comprender la percepción de los estudiantes de odontología de una institución pública brasileña sobre su inserción en lo concreto del Sistema Brasileño de Salud (SUS), en particular en los territorios de la Estrategia Salud de la Familia (ESF) y las posibles contribuciones de este proceso en sus formaciones académicas. Es un estudio de caso analítico, de abordaje cualitativo realizado con discentes, mediante grupos focales con guiones semi-estructurados, asociados al análisis de portafolios elaborados por dichos sujetos, por el análisis de contenido. A partir de la mirada del estudiante de graduación, que a veces ocupa un papel de protagonista y otras de coadyuvante, se observaron elementos importantes en la perspectiva del fortalecimiento del SUS y simultáneamente de su propia formación, en el diapasón de la integración enseñanza/servicio/ comunidad. Los discentes perciben el territorio de la ESF como un escenario de aprendizaje vivo y potente que aproxima al estudiante de los servicios de salud y de sus usuarios.

Palabras clave: Sistema Brasileño de Salud. Atención básica. Enseñanza en odontología. Aprendizaje. 